\title{
Pesticides in Agricultural Run Offs Affecting Water Resources: A Study of Punjab (India)
}

\author{
Tejinder Kaur, Anil Kishore Sinha \\ Department of Anthropology, Panjab University, Chandigarh, India \\ Email: kaurtejinder1985@gmail.com,ksinha_anil@yahoo.com
}

How to cite this paper: Kaur, T. and Sinha, A.K. (2019) Pesticides in Agricultural Run Offs Affecting Water Resources: A Study of Punjab (India). Agricultural Sciences, 10, 1381-1395.

https://doi.org/10.4236/as.2019.1010101

Received: July 18, 2019

Accepted: October 26, 2019

Published: October 29, 2019

Copyright (c) 2019 by author(s) and Scientific Research Publishing Inc. This work is licensed under the Creative Commons Attribution-NonCommercial International License (CC BY-NC 4.0). http://creativecommons.org/licenses/by-nc/4.0/

\begin{abstract}
Background: The pesticides belong to a category of chemicals used worldwide as herbicides, insecticides, fungicides, rodenticides, nematicides, and plant growth regulators in order to control weeds, pests and diseases in crops as well as for health care of humans and animals. The positive aspect of pesticide use renders enhanced crop/food productivity and drastic reduction of vector-borne diseases. On the other hand, excess use of fertilizers threatens the groundwater and surface water on a large scale. Agricultural runoff is surface water leaving cultivated fields as a result of receiving water in excess of the infiltration rate of the soil. Pesticides can enter water through surface runoff or through leaching. These two fundamental processes are linked to the earth's hydrologic cycle. Methodology: Data for the present study were collected from two villages, Arnetu of Patiala District and Wallipur of Ludhiana District of Punjab, India, from the year 2017 to 2018. Data on the frequency of pesticide use, demographic profile, and the concentration of heavy metals in edible vegetables were collected by using structured schedule, case study, and in-depth interview from a total of 250 respondents. Elemental analysis of vegetable samples was carried out with the help of Energy Dispersive X-Ray Florescence (EDXRF). Objectives: a) assessment of pesticide use and its frequency among the farmers of the studied areas; $b$ ) to ascertain potential health risk of pesticide concentrations in runoff from field-sized agricultural watersheds and in rivers and streams and its impact on the residents of the field area (Figure 1 \& Figure 2); c) to collect cases of effected families. Results: It was reported that $80 \%$ and $81 \%$ of respondents from Arnetu and Wallipur village respectively used pesticide in agricultural fields. The frequency of pesticide use was $60 \%$ of the respondents from Arnetu and $70 \%$ from Wallipur village reported that their use of pesticides depends upon the type of crops they have cultivated. The area observed leaching (vertical downward displacement of pesticides through the soil profile and the unsaturated zone, and finally to groundwater) of fertilizers and pesticides frequently oc-
\end{abstract}


curring due to rain or due to irrigation water. It had an indirect impact on the health of the residents. The results of the analytical analysis of vegetables suggested that all the vegetables. Were contaminated maximally by some of the heavy metals. Chromium (Cr), Manganese (Mn), Nickel (Ni), Copper $(\mathrm{Cu})$, Lead $(\mathrm{Pb})$, Cadmium $(\mathrm{Cd})$ and Uranium $(\mathrm{U})$ had been found to be present in higher amounts. The concentrations of these heavy metals in all the vegetable samples were higher than the (US EPA/IS/WHO/BIS) guideline values. The prevalence of cancer and Hepatitis $\mathrm{C}$ was found in Wallipur village where $81 \%$ respondents supported pesticide application in their field. Conclusions: Thus, the present study reflects the adverse health effects of the pesticides' use on groundwater which in turn indirectly is affecting human health. The entire realm of pesticide use reveals a certain un-certainty of situations in which the residents of studied areas are undergoing life-long exposures.

\section{Keywords}

Irrigation Water, Pesticides, Agricultural Runoffs, Ground Water, EDXRF

\section{Introduction}

Adsorption, degradation, and movement are the key processes conditioning the behaviour and fate of pesticides in the soil. Cotton, corn, fruits and vegetables receive the greatest amounts of insecticides, herbicides and fungicides, respectively. Despite pesticide use, crop losses due to pests and disease probably exceed $30 \%$ of total production [1]. Pesticides are chemicals which is toxic to living organisms at sufficiently high levels and are non-toxic at sufficiently low levels.

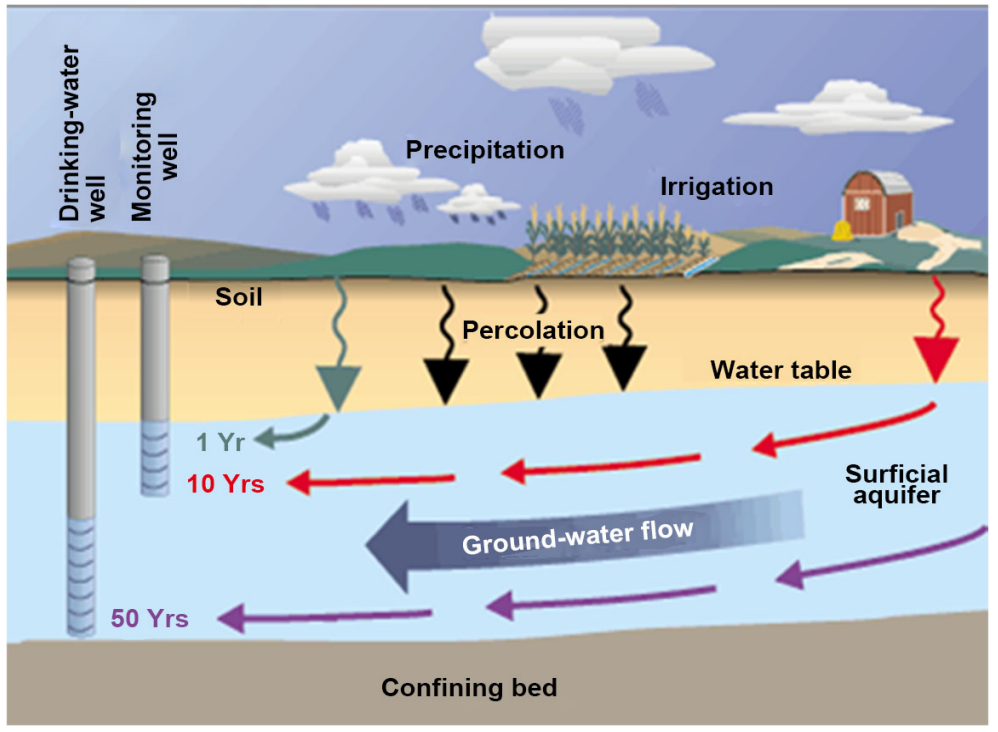

Figure 1. Diagrammatic representation of fertilizers and pesticides contaminating the ground water. 


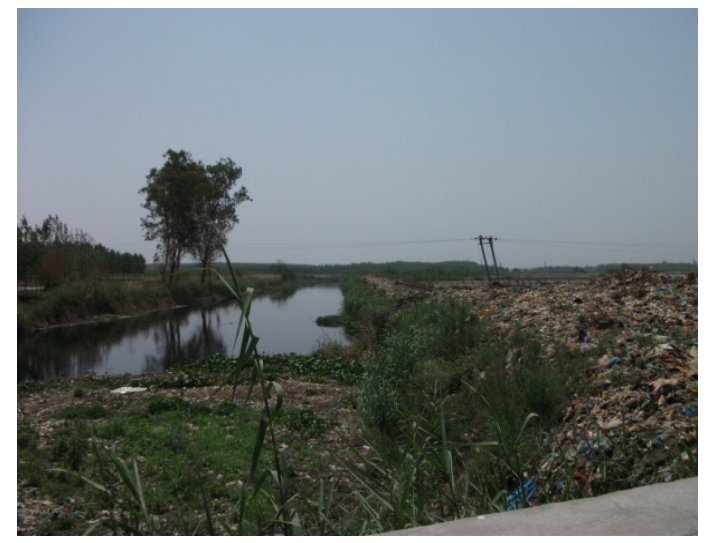

Figure 2. Picture depicting heaps of garbage lying near the agricultural field of study area.

Agricultural pesticides have the potential for biological impact throughout the environment because of the continuous exchange of pesticides among soils, living organisms, water and air.

Agricultural runoff is surface water leaving cultivated fields as a result of receiving water in excess of the infiltration rate of the soil [2]. Water that flows across the surface, whether from rain, irrigation, or other water released onto the surface, always flows downhill until it meets with a barrier, a body of water, or begins to percolate into the soil. There is a worldwide alarm about the impact of agriculture on the environment and the movement of agrochemicals from target to the groundwater. As the runoff moves, it picks up and carries away natural and human-made pollutants, finally depositing them into watersheds through lakes, rivers, wetlands, coastal waters, and even our underground sources of drinking water. Farmers use many agrochemicals to attain highest yields which frequently have consequences for the nearby natural or/and semi-natural adjacent areas. The routes, that the pesticide pollutants may take to reach surface or groundwater enters an established body of water or backs-up behind a barrier and carries with it the dissolved materials that it picked up in the media through which it flowed.

The present paper emphasizes the increasing fears of chemicals used in agriculture which has ultimately found their way into drinking water creating health concerns. Though a number of chemicals have no such effects but gradually with time these chemicals move into groundwater sinking slowly and finally entering the drinking water taps. Use of fertilizers and pesticides not only increases manifold to meet the food needs arising out of population explosion but also further aggravate the situation. According to National Water Quality Inventory (2000), the agricultural nonpoint source (NPS) pollution is the leading source of water quality impacts on surveyed rivers and lakes, the second-largest source of impairments to wetlands, and a major contributor to contamination of surveyed estuaries and ground water. Pesticides deposited on plant and soil surfaces may be transported in runoff from land to aquatic habitats in true solution, as small, 
un-dissolved particles, bound to eroded soil particles and plant debris or dissolved in humate material.

Pesticides have important benefits in crop protection, food and material preservation, and disease control although unfortunately can pose undesirable effects on human health and environmental ecosystems. The use of pesticides in agriculture is necessary to combat a variety of pests and diseases that could destroy crops and to improve the quality of the food produced. A pesticide also is called as plant protection product (PPP) is any "substance intended for preventing, destroying, repelling, or mitigating any pest in crops either before or after harvest to prevent deterioration during storage or transport." Excess use of fertilizers and pesticides in agricultural activities to enhance productivity due to rapid population increase and development of technology threaten the groundwater and surface water on a large scale. In most of the countries, soils and waters have been polluted by fertilizers and pesticides used during agricultural activities. These waters and soils continue to be polluted, as the necessary precautions have not been taken. This shows there is an obvious risk for human in the future [3]. However, the unregulated and indiscriminate applications of pesticides have raised serious concerns about the entire environment in general and the health of humans in particular. The factors affecting water pollution with pesticides and their residues include drainage, rainfall, microbial activity, soil temperature, treatment surface, application rate as well as the solubility, mobility and half-life of pesticides. There is a concern worldwide about the impact of agriculture on the environment and the migration of agrochemicals from their target to the groundwater. To attain the highest yields, farmers use many agrochemicals and practices, which frequently have repercussions for the nearby natural or/and semi-natural adjacent areas. Environmental pollution is concerned problem all around world due to rapid increase of industrialization and urbanization. Especially, the intensive pesticide use has caused some environmental problems in many countries. Therefore, there is a need to protect the resources from the pesticides contamination for future sustainable use.

Once a pesticide is applied to soil, it follows one of three pathways: 1) adhering to soil particles (mainly organic matter and clays); 2) degrading by organisms and/or free enzymes; and 3) moving through the soil with water. From the physical-chemical data of adsorption, mobility, and degradation obtained in the laboratory, it is possible to predict with a high degree of reliability the behaviour of pesticides in the soil. For this, different guidelines have been proposed by OECD to study adsorption [4], degradation [5], and leaching [6].

Pollutants that result from farming and ranching include sediment, nutrients, pathogens, pesticides, metals, and salts. In arid areas, for example, where rainwater does not carry minerals deep into the soil, evaporation of irrigation water can concentrate salts. Excessive irrigation can affect water quality by causing erosion, transporting nutrients, pesticides, and heavy metals, or Insecticides, herbicides, and fungicides can enter and contaminate water through direct applica- 
tion, runoff, and atmospheric deposition. They can contaminate food sources, and destroy the habitat that animals use for protective cover. To reduce contamination from pesticides, it is advisable to the farmers to use Integrated Pest Management (IPM) techniques based on the specific soils, climate, pest history, and crop conditions for a particular field. IPM encourages natural barriers and limits pesticide use and manages necessary applications to minimize pesticide movement from the field decreasing the amount of water that flows naturally in streams and rivers.

The point sources of pollution such as municipal sewer systems usually enter the water body via pipes and it is comparatively easy to collect such water and reroute it through a treatment system prior to releasing it into the environment. Because of the NPS nature of agricultural runoff, efforts to minimize or eliminate pollutants are focused on practices to be applied oil near cultivated fields themselves. Agricultural runoff is considered to be the primary source of pollutants to streams and lakes, as well as estuaries. Runoff from agricultural fields introduces soil, organic matter, manure, fertilizer and pesticides into small-streams, increasing the volume of stream discharge and changing water quality.

Water quality and agriculture are closely linked because of the potential NPS pollution of lakes, rivers, streams, etc. by agricultural runoff [7] [8]. Contaminants such as sediments, bacteria (e.g. dairy waste), nutrients (e.g. nitrogen and phosphorus), and pesticides may be transported from agricultural fields during rainstorm runoff events. As according to [9], pesticides have played a key role against food shortages and vector-borne diseases, and humankind would be vastly different without their use. However, non-target impacts from pesticide associated agricultural runoff persist.

One of the most direct methods of controlling pollution from agricultural runoff is to minimize the potential for runoff. Other methods such as best management practices can be used to reduce the amounts of sediments and dissolved chemicals in surface runoff. Control of water pollution in agricultural runoff is often effectively achieved by reducing soil erosion from the field, and the primary method of doing this is by maintaining some type of plant cover on the soil surface or reducing the area of bare soil [9] [10] [11]. Techniques include conservation tillage, strip tillage, plant strips, and the use of cover crops. Additional measures that can be employed at the edge of the field, or off-site, include farm ponds and vegetative filter strips, especially during critical runoff/erosion periods.

The Malwa region of Punjab, India, is facing an unprecedented crisis of environmental health linked to indiscriminate, excessive, and unsafe use of pesticides, fertilizers, and poor groundwater quality. The region has been described as India's "cancer capital" due to abnormally high number of cancer cases, which have increased 3-fold in the last 10 years. Studies of this region have also highlighted a sharp increase in many other pesticide-related diseases, such as mental retardation and reproductive disorders. The most affected individuals are the agricultural workers who are directly exposed to pesticides. 


\section{Research Methodology}

The Malwa region of Punjab, India, is less than 15\% of the total area of Punjab (only $0.5 \%$ of the total geographical area of India), but it consumes nearly $75 \%$ of the total pesticides used in Punjab. The high use of pesticides, along with environmental and social factors, is responsible for the high concentration of pesticide residues in the food chain of this region [12]. Data for the present study was collected from two villages, Arnetu of Patiala District and Wallipur of Ludhiana District of Punjab, India, from the year 2017 to 2018. Data on the frequency of pesticide use, demographic profile, and the concentration of heavy metals in edible vegetables were collected by using structured schedule, case study, and in-depth interview from a total of 250 respondents. Respondents were interviewed using structured schedule, case study, and in-depth Interview. Elemental analysis of vegetable samples was carried out with the help of Energy Dispersive X-Ray Florescence (EDXRF).

Objectives: a) assessment of pesticide use and its frequency among the farmers of the studied areas; b) to ascertain potential health risk of pesticide concentrations in runoff from field-sized agricultural watersheds and in rivers and streams and its impact on the residents of the field area (Figure 1 \& Figure 2); c) to collect cases of effected families.

\section{Results}

It was reported that $80 \%$ and $81 \%$ respondents from Arnetu and Wallipur village respectively used pesticide in agricultural fields. Whereas, only $20 \%$ from Arnetu and 19\% from Wallipur did not knew anything regarding the use of pesticide. The usage of pesticide in both the study areas were found to be highly significant $(p<0.001)$. The frequency of pesticide use in Figure 3 depicts that $69 \%$ of the respondents from Arnetu and $72 \%$ from Wallipur village reported that their use of pesticides depend upon the type of crops they have cultivated. Very few, $11 \%$ from Arnetu and $9 \%$ from Wallipur village supported the view that they generally cultivate wheat in their field and the frequency of pesticide use in wheat field is thrice in the whole crop season. Initially herbicide is sprayed to clear the unwanted plants like climbers and creepers. Later pesticide is used to control pests and weeds.

The studied area observed leaching (vertical downward displacement of pesticides through the soil profile and the unsaturated zone, and finally to ground water) of fertilizers and pesticides frequently occurring due to rain or due to irrigation water. It had an in direct impact on the health of the residents. The prevalence of Cancer and Hepatitis C was found in Wallipur village where $81 \%$ respondents supported pesticide application in their field.

Health data of successive 6 years was collected from the Anganwadi workers and Primary Health Centres (PHC) of both the studied areas, Area 1 (Arnetu village) \& Area 2 (Wallipur village). Figure 4 shows the crude death rate of the studied areas. The data in the first figure is in accordance to the Anganwadi worker whereas the data in the second figure is in accordance to the PHC. 


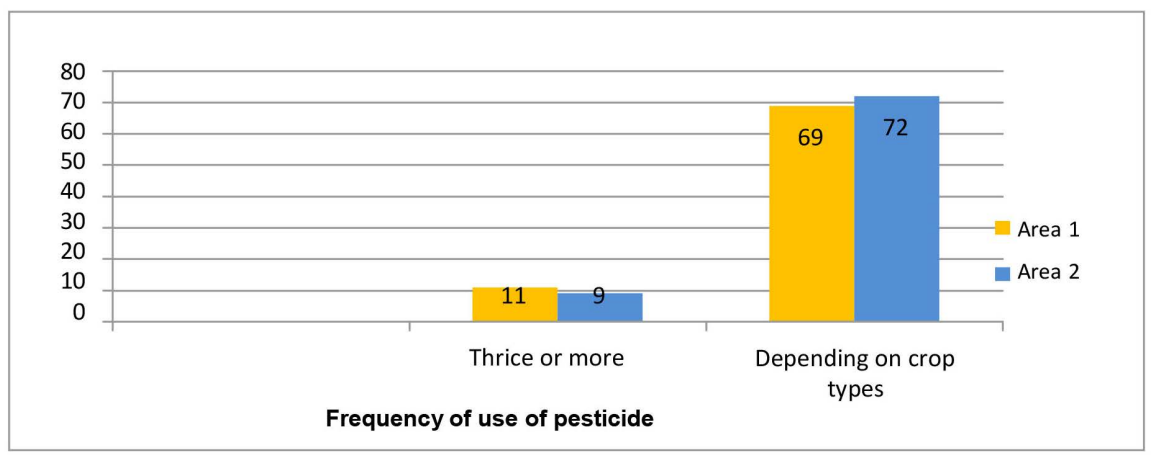

Figure 3. Frequency of pesticide use.

The Crude Death Rate (CDR) data of the field areas has been shown in Figure 4. Data according to Anganwadi worker is given in the first figure, which shows a steady fall from 2009 to 2011 in Arnetu village followed by a rise from 2011 to 2012, and which again shows a declining trend till 2013. The Crude Death Rate of Wallipur village showed a steady decline from 2009 to 2010. The graph further rises from 2010 to 2012 followed by a decline from 2012 to 2013. The data collected from (PHC) is given in the second figure. The figure showed a steady decline from 2010 to 2014 in Arnetu village. The CDR of Wallipur village showed a decline from 2010 to 2011 which further inclines in 2012. The graph thereafter showed an incline from 2013 to 2014.

The documented cases of pesticide concentrations revealed the agony and miserable story of the sickly. The moving water was chocked with dead plants at certain places; due to this the surrounding areas were unfit for human habitation and made the life of the residents miserable. Some respondents narrate agriculture being the major occupation of the people of this village. In order to protect the crops from losses due to pests and diseases, "we are using huge quantities of pesticides on our agricultural fields". According to a few respondents, the water had leached into the ground water causing the underground water to pollute and which ultimately with time had made the underground water unfit for drinking. During the rainy seasons heap of solid waste, plants residues and also the pesticides sprayed on the plants gets washed off with the rain water and get mixed in to the underground water.

As quoted by another resident a crane was also seen to pull out the garbage from the nullah water and dispose it off somewhere far from the nullah so that during rains it may not get mixed into the nullah again. The crane came only once that too under political pressure and may be the villagers had made an appeal "to the Sarpanch to clean the nullah which is a house of a number of diseases". Due to the conflict between two political parties in the village if one of the party was in favour of the welfare of the village the opposition party opposed.

However, both essential and toxic components are available in vegetables over an extensive variety of concentrations as they are said to be great absorber of 


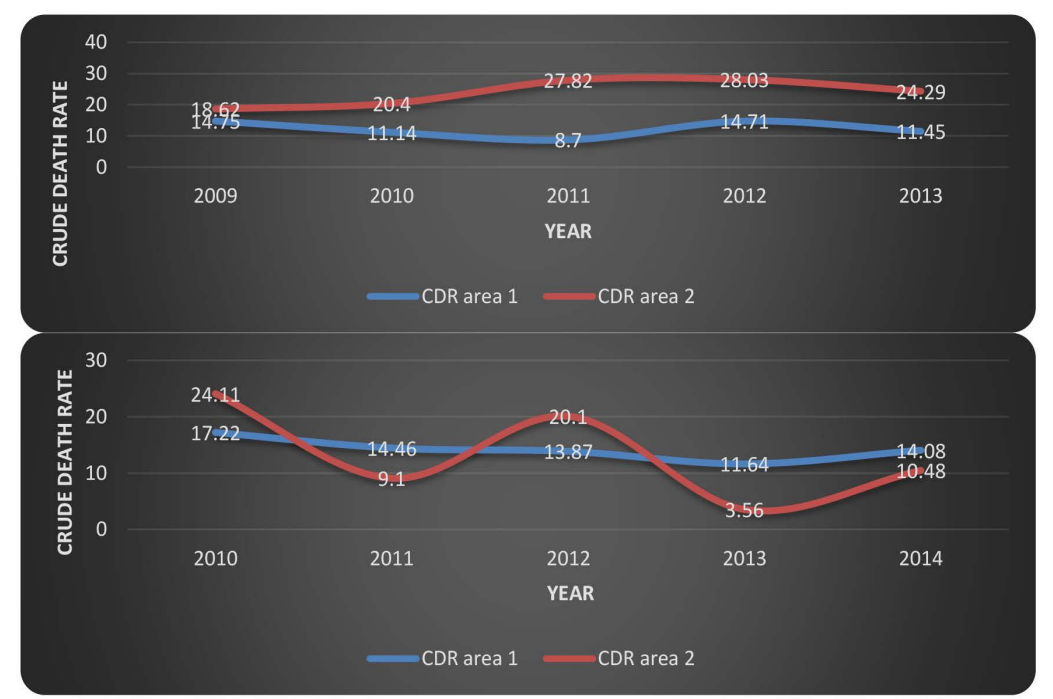

Figure 4. Showing trend in crude death rate in Area $1 \&$ Area 2.

metals from the soil [13]. The analytical analysis of vegetables grown along the sides of the River Ghaggar has been shown in Table 1. The results suggest that all the vegetables tested were contaminated maximally by some of the heavy metals. Chromium (Cr), Manganese (Mn), Nickel (Ni), Copper $(\mathrm{Cu})$, Lead $(\mathrm{Pb})$, Cadmium (Cd) and Uranium (U) had been found to be present in higher amounts. The concentrations of these heavy metals in all the vegetables samples were higher than the (US EPA/IS/WHO/BIS) guideline values.

The Cadmium concentration in the present study was found to be high in almost all vegetables except for in cabbage and very smaller amount in garlic. The levels of Uranium in tomato were found beyond the permissible limits. It was also found that the concentration of $\mathrm{Pb}, \mathrm{Zn}, \mathrm{Cu}$ and Fe were considerably high in the present study. The presence of Manganese in the present study was of the order of Cauliflower $>$ Spinach $>$ Tomato $>$ Cabbage $>$ Garlic.

The analytical analysis of river water/water bodies are presented in Table 2. In the present study the distribution of heavy were measured in surface river water and the bed of the river with the aim to monitor the impacts of heavy metals on the water quality. The table showed that the contents of the heavy metals: Chromium (Cr), Manganese (Mn), Nickel (Ni), Zinc (Zn), Antimony (Sb), Tin (Sn), Lead $(\mathrm{Pb})$, Strontium $(\mathrm{Sr})$, Cadmium $(\mathrm{Cd})$, Uranium $(\mathrm{U})$, Titanium (Ti) were higher than the safe limits prescribed by various organisations and agencies (US $\mathrm{EPA} / \mathrm{WHO} / \mathrm{IS}$ ) involved in environmental pollution control.

Among these several heavy metals, like cadmium, lead, Uranium, Strontium and Zinc are highly toxic at relatively low concentrations, can accumulate in body tissues over long periods of time, and are nonessential for human health. The metal distribution pattern of the Ghaggar River and Buddha Nullah clearly indicates the source of pollution to be land-based and implicates the industries in the adjacent area as the most likely source. 
Table 1. Analytical analysis of vegetable samples.

\begin{tabular}{|c|c|c|c|c|c|c|c|c|c|}
\hline Elements & Tomato & Cauli-flower & Garlic & Spinach & Cabbage & Average & SD & Range & Permissible range \\
\hline $\mathrm{Ca}$ & 97.1 & 297.8 & 224.4 & 173.7 & 519 & 262.4 & 144.04 & 97.1 to 519 & $\begin{array}{l}75 \mathrm{mg} / \mathrm{l} \\
\text { (IS:1993) }\end{array}$ \\
\hline $\mathrm{Cr}$ & 28.1 & 42.9 & 25.1 & 25.7 & 9.9 & 26.34 & 10.48 & 9.9 to 42.9 & $\begin{array}{l}0.05 \mathrm{mg} / 1 \\
\text { (IS:1993) }\end{array}$ \\
\hline $\mathrm{Mn}$ & 96.5 & 160.6 & 84.6 & 144.4 & 48.1 & 106.84 & 40.87 & 48.1 to 160.6 & $\begin{array}{l}0.1 \mathrm{mg} / 1 \\
\text { (IS:1993) }\end{array}$ \\
\hline $\mathrm{Fe}$ & 0 & 86.7 & 0 & 117.5 & 3.1 & 41.46 & 50.47 & 0 to 117.5 & $\begin{array}{l}0.3 \mathrm{mg} / 1 \\
(\mathrm{IS}: 1993)\end{array}$ \\
\hline Co & 3.4 & 3.5 & 1.7 & 1.2 & 1.6 & 2.28 & 0.97 & 1.2 to 3.5 & ------- \\
\hline $\mathrm{Ni}$ & 0 & 29.8 & 0 & 0 & 0 & 5.96 & 11.92 & 0 to 29.8 & $\begin{array}{c}0.02 \mathrm{mg} / 1 \\
\text { (WHO:1993) }\end{array}$ \\
\hline $\mathrm{Cu}$ & 27.3 & 69.4 & 29.7 & 42 & 13.2 & 36.32 & 18.90 & 13.2 to 69.4 & $\begin{array}{c}0.05-0.5 \mathrm{mg} /(\mathrm{IS}: 1991 \text {, } \\
\text { WHO:1993) }\end{array}$ \\
\hline $\mathrm{Zn}$ & 26.8 & 111.8 & 40.3 & 99.1 & 73 & 70.2 & 32.71 & 26.8 to 111.8 & $\begin{array}{c}5 \text { - } 15 \text { mg/l (IS:199/l, } \\
\text { WHO:1993) }\end{array}$ \\
\hline As & 0 & 0 & 0 & 0 & 0 & 0 & 0 & 0 to 0 & $\begin{array}{l}0.05 \mathrm{mg} / 1 \\
\text { (IS:1993) }\end{array}$ \\
\hline $\mathrm{Sb}$ & 0 & 96 & 75 & 57 & 0 & 45.6 & 39.23 & 0 to 96 & $\begin{array}{c}0.005 \mathrm{mg} / 1 \\
\text { (WHO:1993) }\end{array}$ \\
\hline $\mathrm{Ag}$ & 4.4 & 0 & 0 & 0 & 4.3 & 1.74 & 2.13 & 0 to 4.4 & ------- \\
\hline Sn & 2.3 & 3 & 1.5 & 1.3 & 1.1 & 1.84 & 0.71 & 1.1 to 3 & -------- \\
\hline Mo & 0 & 0 & 0 & 0 & 0 & 0 & 0 & 0 to 0 & $\begin{array}{c}0.07 \mathrm{mg} / \mathrm{l} \\
\text { (WHO:1993) }\end{array}$ \\
\hline $\mathrm{Bi}$ & 0 & 0 & 0 & 0 & 0 & 0 & 0 & 0 to 0 & ------- \\
\hline $\mathrm{Pb}$ & 1.1 & 2.2 & 0.8 & 0.8 & 1.2 & 1.22 & 0.52 & 0.8 to 2.2 & $\begin{array}{c}0.01 \mathrm{mg} / 1 \\
\text { (WHO:1993) }\end{array}$ \\
\hline $\mathrm{Sr}$ & 1.1 & 0 & 0 & 5.1 & 8.8 & 3 & 3.45 & 0 to 8.8 & ------- \\
\hline $\mathrm{Cd}$ & 6.7 & 1.8 & 0.4 & 2.2 & 0 & 2.22 & 2.39 & 0 to 6.7 & $\begin{array}{c}0.003 \\
\mathrm{mg} / \mathrm{l}(\mathrm{WHO}: 1993)\end{array}$ \\
\hline $\mathrm{U}$ & 1.4 & 0 & 0 & 0 & 0 & 0.28 & 0.56 & 0 to 1.4 & $\begin{array}{c}0.03 \mathrm{mg} / 1 \\
\text { US EPA }\end{array}$ \\
\hline $\mathrm{Hg}$ & 0 & 0 & 0.6 & 0 & 0 & 0.12 & 0.24 & 0 to 0.6 & $\begin{array}{c}0.001 \\
\mathrm{mg} / \mathrm{l}(\mathrm{WHO}: 1993)\end{array}$ \\
\hline
\end{tabular}

\section{Discussion}

Modern agriculture relies heavily on pesticides benefitting to mankind by controlling insect vectors of disease and thereby increasing yields of many crops. The study area experienced agricultural runoff saturated with nutrients and fertilizers and the inflow of soil particles which takes place during monsoons. Sources of water pollution in the field area includes industrial effluents, domestic wastewater containing detergents and agricultural run-off saturated with pesticides, insecticides, fertilizers and other nutrients, decaying of animal, plant and nitrogenous waste disposed from domestic and industrial processes [14]. 81\% of respondents supported pesticide application in their field and the concentration of insecticides/pesticides was observed in all seasons. Data from the study area revealed that a large number of respondents used pesticides in their fields. Also, the frequency of its use depends upon the type of crop. The prevalence of Cancer 
Table 2. Analytical analysis of the River Water/Water Bodies.

\begin{tabular}{|c|c|c|c|}
\hline \multirow{2}{*}{ Elements } & $\begin{array}{l}\text { Buddha Nullah } \\
\text { (Water stream) }\end{array}$ & $\begin{array}{c}\text { Ghaggar } \\
\text { (River water) }\end{array}$ & \multirow{2}{*}{ Desirable Limits (ppm) } \\
\hline & $\begin{array}{c}\text { Mean } \\
(\mathrm{ppm}) \mathrm{N}=3\end{array}$ & $\begin{array}{c}\text { Mean } \\
(\mathrm{ppm}) \mathrm{N}=3\end{array}$ & \\
\hline $\mathrm{Ca}$ & 0.55 & 0.23 & 75mg/l (IS:1991) \\
\hline $\mathrm{Cr}$ & 2.65 & 3 & 0.05 mg/l (IS:1991) \\
\hline $\mathrm{Mn}$ & 0.95 & 1.5 & $0.1 \mathrm{mg} / \mathrm{l}$ (IS:1991) \\
\hline $\mathrm{Fe}$ & 26.05 & 0 & $0.3 \mathrm{mg} / \mathrm{l}$ (IS:1991) \\
\hline Co & 3.65 & 5.4 & ------- \\
\hline $\mathrm{Ni}$ & 0.35 & 2.1 & $0.02 \mathrm{mg} / \mathrm{l}$ (WHO:1993) \\
\hline $\mathrm{Cu}$ & 15.6 & 19.5 & 0.05 mg/l ( IS:1991) \\
\hline $\mathrm{Zn}$ & 7.05 & 3.83 & 5 mg/l (IS:1991) \\
\hline As & 0 & 0 & 0.01 mg/l (IS:1991) \\
\hline $\mathrm{Sb}$ & 67.5 & 52 & $0.005 \mathrm{mg} / \mathrm{l}((\mathrm{WHO}: 1993)$ \\
\hline $\mathrm{Ag}$ & 23.75 & 0 & $0.1 \mathrm{mg} / \mathrm{l}$ (IS:1991) \\
\hline Sn & 3.7 & 4.53 & No limits listed \\
\hline Mo & 0 & 0 & $0.07 \mathrm{mg} / \mathrm{l}((\mathrm{WHO}: 1993)$ \\
\hline $\mathrm{Bi}$ & 0 & 0 & ------- \\
\hline $\mathrm{Pb}$ & 6.8 & 7.83 & $0.01 \mathrm{mg} / \mathrm{l}$ (WHO:1993) \\
\hline $\mathrm{Sr}$ & 0 & 0.23 & No limits listed \\
\hline $\mathrm{Cd}$ & 1.2 & 0.83 & $0.003 \mathrm{mg} / \mathrm{l}$ (WHO:1993) \\
\hline $\mathrm{U}$ & 0.55 & 0.8 & $30 \mu \mathrm{g} / 1 \mathrm{US}$ EPA \\
\hline $\mathrm{Hg}$ & 0 & 0 & $0.001 \mathrm{mg} / \mathrm{l}$ (WHO:1993) \\
\hline $\mathrm{Se}$ & 0 & 0 & $0.05(\mathrm{mg} / \mathrm{l})$ US EPA \\
\hline $\mathrm{Tl}$ & 3.2 & 0 & No limits listed \\
\hline I & 0 & 0 & ------ \\
\hline
\end{tabular}

and Hepatitis C was found in Wallipur village where $81 \%$ of respondents supported pesticide application in their field.

Highest pesticide concentration in the field during post monsoon period may be due to increased surface runoff due to rain fall, as main source of pesticide contamination is agricultural runoff saturated with wide range of pesticides. Similar effect of rain on pesticide contamination was reported in river Yamuna [15] and river Ganga [16].

It is important that solutions for agrochemical waste management on farm are effective and safe to the environment; however it is equally important that they are practical, economic and do not over burden the farmer. The data on frequency of pesticide use revealed that $80 \%$ and $81 \%$ respondents from Arnetu and Wallipur village respectively used pesticide in agricultural fields. Whereas, only $20 \%$ from Arnetu and $8 \%$ from Wallipur did not knew anything regarding 
the use of pesticide.

Similarly, the use of un-prescribed pesticides in inappropriate doses is not only disturbing the soil conditions but is also destroying the healthy pool of bio-control agents that normally co-exist with the vegetation. These bio-control agents are the friends of agriculture and hence need to be nurtured, cared and developed by reducing the reliance on chemical's use in agriculture [17]. Some pesticides are not only non-biodegradable but also slightly soluble in water. Consequently, when these are sprayed on cropland, these remain adhered to the soil for long periods. During rainfall these tend to be carried as suspended particles into water systems.

Spontaneous abortion (20.6 per 1000 live births) and premature births (6.7 per 1000 live births) were significantly higher in area affected by heavy metal and pesticide pollution $(\mathrm{p}<0.05)$. Stillbirths were about five times higher as compared with a meta-analysis for south Asian countries. A larger proportion of children in target area were reported to have delayed milestones (also called developmental delays), language delay, blue line in the gums, mottling of teeth and gastrointestinal morbidities $(\mathrm{p}<0.05)$. Although no direct association was established in the study, the results showed that heavy metal and pesticide exposure may be potential risk factors for adverse reproductive and child health outcomes.

Few narrations by the respondents where "during the monsoons the situation gets aggravating due to washing off of chemical fertilizers and pesticides that would seep deep inside into the soil" (Figure 4); also "the waste and the garbage of the river lying along the bank with the passage of time simultaneously was added to the agricultural field" (Figure 2).

As mentioned earlier the industries in Punjab are throwing its untreated toxic waste water into water streams. Heavy metal contamination of soil and water was a cause of serious concern due to the potential health impacts of consuming contaminated produce. The heavy metal concentrations in the river water were remarkably high and were not within the permissible limits in the present study. Similar trend has been seen in a study by [18]. The distribution of heavy metals ( $\mathrm{Al}, \mathrm{Ba}, \mathrm{Cd}, \mathrm{Co}, \mathrm{Cr}, \mathrm{Cu}, \mathrm{Fe}, \mathrm{Mn}, \mathrm{Ni}, \mathrm{Pb}$ and $\mathrm{Zn}$ ) in surface water and river sediments were remarkably high, but varied among sampling points, and the concentrations in water were mainly within the permissible limits. The heavy metal contents in bed sediment were highest during closure of winter period. The Cadmium concentration in the present study was found to be high in almost all vegetables except for in cabbage and very smaller amount in garlic. Similar levels were reported by [19] in vegetables grown on soils contaminated by base metal mining in north east Wales and England. Cadmium levels in a study were higher in a study by [20].

Uranium is a ubiquitous constituent of natural environment. Uranium is present in the environment as a result of leaching from natural deposits, release in mill tailings, and emissions from the nuclear industry, the combustion of coal and other fuels and the use of phosphate fertilizers that contain uranium (WHO, 
2004). In the present study the levels of Uranium were found only in tomato beyond the permissible limits. The concentrations of $\mathrm{Pb}, \mathrm{Zn}, \mathrm{Cu}$ and $\mathrm{Fe}$ in vegetables were considerably high in the present study. Similar trend was reported in a study of the long-term effects of municipal waste disposal on soil properties and productivity of sites used for urban agriculture in Abakaliki, where the concentrations of heavy metals in all the vegetable samples in the four locations were higher than the FAO/WHO [21]. Manganese is considered an essential nutrient, because the body requires it to function properly. In the present study it was found that element Manganese was in quite higher amount. The highest mean levels of Mn were detected in mint and spinach [22].

\section{Conclusions}

Pesticides are often believed as quick, easy, and inexpensive solution for controlling weeds and insect pests in urban landscapes. These have contaminated almost every part of our environment as the pesticide residues are found in soil and air and in surface and groundwater across the nation, and urban pesticide uses contribute to the problem. The present research brings forward the issues faced by the two villages related to agricultural runoffs which they regarded as contaminated.

The agricultural runoff containing heavy metals reaches natural water bodies affecting the ecosystem. The use of chemicals in agriculture presents global alarm particularly for Punjab (India) where environmental degradation is uncontrolled causing groundwater contamination resulting from application of agricultural chemicals especially the fertilizer. Heavy metal contamination of soil and water was a cause of serious concern in the field area due to the potential health impacts of consuming contaminated produce. The heavy metal concentrations in the river water were remarkably high and were not within the permissible limits in the present study.

Heavy metals are hazardous contaminants in food and the environment and they are non-biodegradable having long biological half-lives. Vegetables are basic eating routine taken by populations all through the world, being wellsprings of fundamental supplements, antioxidants agents and metabolites. They get contaminated due to the polluted agricultural run-off water used for irrigation. It has been found that contaminated soil and vegetables contribute to a progressive gathering of heavy metals in food chain causing possibility to deep alternations of ecosystem with possible noxious effect on human health. The present research highlights that vegetables growing soil containing higher amount of metals that could be transferred into edible parts of the plant, so study area should be monitored regularly to avoid health risk of human being due to exposure of toxic level.

Thus, the present study reflects the adverse health effects of the pesticides use on ground water which in turn indirectly is affecting human health. The entire realm of pesticide use reveals a certain un-certainty of situations in which the residents of studied areas are undergoing life-long exposures. 


\section{Funding}

UGC, New Delhi has funded the research in conducting fieldwork (by providing travelling allowances and dearness allowances, also the cost of all stationary items was provided by the UGC.

\section{Authors' Contributions}

Dr. Kaur carried out the field-work, analysis of data, framing the results and discussion, and Prof. Sinha wrote the Introduction chapter, Review of Literature and other related chapters.

\section{Acknowledgements}

I sincerely thank UGC, New Delhi for giving Junior Research Fellow (JRF) and Senior Research Fellow (SRF), Department of Anthropology Panjab University, Chandigarh for allowing me to use EDXRF for carrying out the elemental analysis of the vegetables

\section{Conflicts of Interest}

The authors declare no conflicts of interest regarding the publication of this paper.

\section{References}

[1] Ridgway, R.L., Tinney, J.C., MacGregor, J.T. and Starler, N.J. (1978) Pesticide Use in Agriculture. Environmental Health Perspectives, 27, 103-112. https://doi.org/10.1289/ehp.7827103

[2] Zuazo, V.H.D., et al. (2009) Agricultural Runoff: New Research Trends. In: Iudspeth, A.I. and Reeve, T.E., Eds., Agricultural Run Off, Coastal Engineering and Flooding, Nova Science Publishers, New York, 27-48.

[3] Keskin, T.E. (2010) Nitrate and Heavy Metal Pollution Resulting from Agricultural Activity: A Case Study from Eskipazar (Karabuk, Turkey). Environmental Earth Sciences, 61, 703-721. https://doi.org/10.1007/s12665-009-0385-x

[4] Organization for Economic Cooperation and Development (OECD) (2000) Guidelines for Testing of Chemicals, No 106, Adsorption-Desorption Using a Batch Equilibrium Method. Organization for Economic Cooperation and Development (OECD), Paris.

[5] Organization for Economic Cooperation and Development (OECD) (2002) Guidelines for Testing of Chemicals, No 307, Aerobic and Anaerobic Transformation in Soil. Organization for Economic Cooperation and Development (OECD), Paris.

[6] Organization for Economic Cooperation and Development (OECD) (2007) Guidelines for Testing of Chemicals, No 312, Leaching in Soil Columns. Organization for Economic Cooperation and Development (OECD), Paris.

[7] Cooper, C.M. (1993) Agricultural Runoff: New Research Trends in Agricultural Runoff, Coastal. Biological Effects of Agriculturally Derived Surface-Water Pollutants on Aquatic Systems: Review. Journal of Environmental Quality, 22, 402-408. https://doi.org/10.2134/jeq1993.00472425002200030003x 
[8] Maul, J.D. and Cooper, C.M. (2000) Water Quality of Seasonal Flooded Agricultural Fields in Mississippi, USA. Agriculture Ecosystems and Environment, 81, 171-178. https://doi.org/10.1016/S0167-8809(00)00157-2

[9] Francia, J.R., Dllran, Z.V.H. and Martinez, R.A. (2006) Environmental Impact from Mountainous Olive Orchards under Different Soil-Management Systems (SE Spain). Science of Total Environment, 358, 46-60. https://doi.org/10.1016/j.scitotenv.2005.05.036

[10] Martinez, R.A., Duran, Z.V.H. and Francia, F.R. (2006) Soil Erosion and Runoff Response to Plant Cover Strips Oil Slopes (SE Spain). Land Degradation and Development, 17, 1-11. https://doi.org/10.1002/ldr.674

[11] Duran, Z.V., RodrIgLlcz, P.C.R., Francia, M.J.R., Carceles, R.B., Martinez, R.A., et al. (2008) Harvest Intensity of Aromatic Shrubs vs. Soil-Erosion: An Equilibrium for Sustainable Agriculture (SE Spain). Catena, 73, 107-116. https://doi.org/10.1016/j.catena.2007.09.006

[12] Sunil, M., Gurpreet, K. and Singh, V.G. (2014) Effects of Environmental Pesticides on the Health of Rural Communities in the Malwa Region of Punjab, India: A Review. Human and Ecological Risk Assessment, 20, 366-387. https://doi.org/10.1080/10807039.2013.788972

[13] Shakya, P.R. and Khwaounjoo, N.M. (2013) Heavy Metal Contamination in Green Leafy Vegetables Collected from Different Market Sites of Kathmandu and Their Associated Health Risks. Scientific World, 11, 37-42. https://doi.org/10.3126/sw.v11i11.8550

[14] Makhijani, S.D. and Manoharn, A. (1999) Nitrate Pollution Problem in Drinking Water Sources: Monitoring and Surveillance. Water Quality Field Test Kits for Arsenic, Fluoride and Nitrate ITRC, Lucknow, 8-9 September 1999.

[15] Kaushik, C.P., Sharma, H.R., Jain, S., Dawra, J. and Kaushik, A. (2008) Pesticide Residues in River Yamuna and Its Canals in Haryana and Delhi, India. Environmental Monitoring Assessment, 144, 329-340. https://doi.org/10.1007/s10661-007-9996-4

[16] Agnihotri, N.P., Gajbhiye, V.T., Kumar, M. and Mohapatra, S.P. (1994) Organochlorine Insecticide Residues in Ganga River Water near Farrukhabad, India. Environmental Monitoring and Assessment, 30, 105-112. https://doi.org/10.1007/BF00545617

[17] Abhilash, P.C. and Singh, N. (2009) Pesticide Use and Application: An Indian Scenario. Journal of Hazardous Material, 165, 1-12. https://doi.org/10.1016/j.jhazmat.2008.10.061

[18] Bouraie, E.L., Mohamed, M., Ahmed, A., Barbary, E.L., Yehia, M.M. and Motawea, E.A. (2010) Heavy Metal Concentrations in Surface River Water and Bed Sediments at Nile Delta in Egypt. Suoseura-Finnish Peatland Society, 61, 1-12.

[19] Davies, B.E. and White, H.M. (1981) Trace Elements in Vegetables Grown on Soils Contaminated by Base Metal Mining. Journal of Plant Nutrition, 3, 387-396. https://doi.org/10.1080/01904168109362846

[20] Kachenko, A.G. and Balwant, S. (2006) Heavy Metals Contamination in Vegetables Grown in Urban and Metal Smelter Contaminated Sites in Australia. Water Air and Soil Pollution, 169, 101-123. https://doi.org/10.1007/s11270-006-2027-1

[21] Akan, J.C., Kolo, B.G., Yikala, B.S. and Ogugbuaja, V.O. (2013) Determination of Some Heavy Metals in Vegetable. Samples from Biu Local Government Area, Borno State, North Eastern Nigeria. International Journal of Environmental Monitoring and Analysis, 1, 40-46. https://doi.org/10.11648/j.ijema.20130102.11 
[22] Arora, M., Kiran, B., Shweta, R., Anchal, R., Barinder, K., et al. (2008) Heavy Metal Accumulation in Vegetables Irrigated with Water from Different Sources. Food Chemistry, 111, 811-815. https://doi.org/10.1016/j.foodchem.2008.04.049

\section{List of Abbreviations}

EDXRF: Energy Dispersive X-Ray Florescence

USEPA: United States Environmental Protection Agency

BIS: The Bureau of Indian Standards

WHO: World Health Organization

Cr: Chromium

Mn: Manganese

Ni: Nickel

$\mathrm{Cu}$ : Copper

Pb: Lead

Cd: Cadmium

U: Uranium

NPS: Nonpoint source

PPP: Plant Protection Product

OECD: The Organisation for Economic Co-operation and Development

IPM: Integrated Pest Management

Anganwadi: "Courtyard Shelter" in Indian languages

PHC: Primary Health Centres

CDR: Crude Death Rate

Nullah: A watercourse, riverbed, or ravine

FAO: Food and Agriculture Organization of the United Nations 